\title{
What role for photoperiod in the bud burst phenology of European beech
}

\author{
Yann Vitasse · David Basler
}

Received: 28 February 2012/Revised: 13 August 2012/ Accepted: 10 October 2012/Published online: 1 November 2012 (C) Springer-Verlag Berlin Heidelberg 2012

\begin{abstract}
A considerable number of studies have investigated the phenology of European beech using models, experimental controlled conditions, or descriptive surveys of patterns in situ. In spite of this interest, there is no consensus about the environmental factors controlling bud burst in beech, especially about the role of photoperiod and chilling temperature (cold temperature effective to release bud dormancy). However, recent experimental and modelling studies provide new insights into the means by which these environmental factors control beech phenology. This present contribution aims to reconcile contradictory hypotheses about the main environmental factors controlling bud burst date of European beech. First, we review the main published results on the environmental control of beech phenology both in controlled and in natural conditions. Second, supported by the findings of recent studies, we propose a new theory for the role of photoperiod during the chilling phase for explaining spatial and temporal variations in bud burst phenology of European beech. Examples using long-term data from the Swiss Alps and Germany are presented to support this theory. The possible impacts of future and ongoing climate warming on beech phenology are discussed. Finally, due to interactions between chilling, forcing temperature, and photoperiod, we assert that beech phenology follows a nonlinear trend across biogeographical gradients such as changes in elevation or latitude and that the bud burst date of beech is
\end{abstract}

Communicated by Uta Berger.

Y. Vitasse $(\varangle) \cdot$ D. Basler

Institute of Botany, University of Basel, 4056 Basel, Switzerland

e-mail: yann.vitasse@unibas.ch

D. Basler

e-mail: david.basler@unibas.ch expected not to undergo significant changes in response to global warming, especially in warmer climates.

Keywords Fagus sylvatica $\cdot$ Spring phenology $\cdot$ Bud burst · Chilling · Photoperiod · Temperature - Climate change

\section{Introduction}

The European beech (Fagus sylvatica L.) is one of the most dominant forest tree species in Europe. Its distribution area is mainly concentrated in the Centre and West of Europe and covers various habitats ranging from mountainous regions in southern and Eastern Europe to lowlands in central Europe (Bolte et al. 2007). That said, and despite the considerable importance of the beginning of the growing season for tree growth (Rötzer et al. 2004; Churkina et al. 2005; Gomory and Paule 2011), tree fitness and tree species distribution area (Chuine 2010), it is surprising that the way environmental factors act on bud burst phenology of beech is still poorly understood. Indeed, among temperate tree species, European beech has always occupied a special place for scientists studying the phenology of trees but nevertheless the accurate prediction of beech bud burst date is still problematic because of various unresolved issues (Kramer 1994). The "apparent" contradictory results found in the literature led to different assumptions about the main environmental factors controlling spatial and temporal variations in bud burst dates of beech. Here, through our critical appraisal of recent findings, we were able to reconcile the conflicting results and propose a new theory for the role of photoperiod during the chilling phase to explain spatial and temporal variations in bud burst dates of European beech. We first review the 
different results reported from observational studies, from experimental manipulations with particular reference to biogeographical gradients, and from modelling studies. Then, we finally test our theory through a new analysis of data from different elevations.

\section{Spatial and temporal patterns of bud burst in nature}

The spring phenological pattern of European beech differs to that of other temperate tree species in two main aspects. First, the bud burst date of beech shows less temporal and spatial variations than most of the other deciduous tree species in Europe. For example, along elevational gradients, beech exhibits a slight delay in leaf unfolding dates, generally less than 20 days $1,000 \mathrm{~m}^{-1}$, whereas other co-occurring tree species, such as Quercus petraea or Larix decidua, delay more than 30 days $1,000 \mathrm{~m}^{-1}$ (Dittmar and Elling 2006; Migliavacca et al. 2008; Vitasse et al. 2009b; Davi et al. 2011; Jochner et al. 2012). During the last decades, the bud burst date of beech shows only low year-to-year variation, especially in mild climates. For instance, beech exhibits the lowest variability in leaf unfolding dates from year to year among the six forest tree species monitored in the same 107 sites in Germany during the period 1980-2009 (Table 1). Furthermore, although climatic warming over the last decades has significantly advanced spring phenology in most deciduous tree species (reviewed by Bertin 2008), European beech has exhibited little or no spring phenological shift during this period (Menzel et al. 2001; Studer et al. 2005; Vitasse et al. 2009a). Accordingly, both spatial and temporal studies have reported relatively little sensitivity of beech bud burst date to spring temperature, with an average advance of 2 days for every $1{ }^{\circ} \mathrm{C}$ increase (Kramer 1995; Vitasse et al. 2009a; Lebourgeois et al. 2010; Kreyling et al. 2012). Second, European beech is considered to be a late-flushing species, compared with most of the co-occurring broad-leaved tree species under mild and warm climates in Europe (Kramer 1995; Gordo and Sanz 2009; Vitasse et al. 2009a). Nevertheless, since tree species can respond to different environmental cues, e.g., photoperiod-sensitive against photoperiod-insensitive species (Körner and Basler 2010; Polgar and Primack 2011), and can have different sensitivity to temperature (Vitasse et al. 2009a), the species ranking for the timing of flushing can also change with climate. For instance, Vitasse et al. (2009b) reported that in the French Pyrenees Mountains, bud burst of beech commenced 20 days later than sessile oak and about one week later than sycamore and European ash at low elevation (below $500 \mathrm{~m}$ ), whereas it commenced one week earlier than those species at high elevation (above 1,500 m). In summary, beech can be considered as a late-flushing species under warm or mild climates, but not necessarily under colder climates within its range.
Table 1 Mean leaf unfolding date (day of the year) and pooled standard deviation (BBCH 11) across 107 sites in Germany from 1980 to 2009

\begin{tabular}{|c|c|c|}
\hline Species & $\begin{array}{l}\text { Mean date of } \\
\text { leaf unfolding }\end{array}$ & Pooled SD \\
\hline Alnus glutinosa & 107.0 & 11.95 \\
\hline Betula pendula & 107.1 & 9.42 \\
\hline Fagus sylvatica & 116.6 & 7.46 \\
\hline Fraxinus excelsior & 126.3 & 9.03 \\
\hline Picea abies ${ }^{\mathrm{a}}$ & 126.4 & 8.63 \\
\hline Quercus robur & 122.1 & 8.06 \\
\hline
\end{tabular}

Only sites where all species are present were selected. Data were provided by the members of the PEP725 Pan European Phenology Data project (Accessed 2011-04-14 at http://www.zamg.ac.at/pep725/)

${ }^{\text {a }}$ Leaf separation $(\mathrm{BBCH} 10)$

\section{What can we learn from experimental studies?}

Many experiments have been conducted using European beech in an attempt to elucidate the biological mechanisms involved in bud dormancy release. This knowledge is crucial for us to understand and predict how trees will respond in different climates. So far, the diversity of often contradictory results from these experiments has proven hard to unify, leaving the environmental controls of dormancy release and beech bud burst poorly understood. However, due to the renewed enthusiasm of researchers to assess the future shift of tree phenology in response to climate warming, several new experimental studies have been conducted, providing a better insight into the different factors involved and their interactions in the mediation of bud burst of European beech.

Evidence of high chilling requirement for dormancy release

Before the 1990s, experimental studies using tree seedlings under controlled conditions generally highlighted the role of chilling temperatures and/or the photoperiod in determining the date of bud burst of some late-leafing species included European beech. For instance, Murray et al. (1989) demonstrated for a set of common European broad-leaved tree species that an increased duration of chilling temperatures led to a decrease in the heating requirement for bud burst. They pointed out that, of this set, beech was unique because it was the only species to never reach its minimal thermal time requirement as long as the previous chilling temperature increased. Based on this result, they suggested that European beech has a very high chilling requirement to fully release bud dormancy, something which was confirmed later by Falusi and Calamassi (1990) and by Caffarra and Donnelly (2011). We applied the same calculation method as Murray 
et al. (1989) to beech phenology data recorded in situ from large elevational gradients and published in Vitasse et al. (2009b), which confirmed that beech seems to have a high chilling requirement (Fig. 1). The increase of the chilling duration exponentially reduces the thermal time to bud burst in sessile oak, among many other tree species (e.g. Murray et al. 1989; Harrington et al. 2010); however, in European beech, there was a linear relationship in our data between thermal time requirement to bud burst and the duration of chilling (Fig. 1). This result would indicate that most of the beech populations monitored in Vitasse et al. (2009b) currently inhabit environments which do not allow the full satisfaction of their chilling requirement, except perhaps for the highest populations which experienced more than 120 days of chilling days over winter (Fig. 1). However, this result should be interpreted with caution, because photoperiod is a confounding factor in situ as it may affect the relationship between forcing (warm temperatures) and chilling requirement (see next section). In addition, the temperature ranges where chilling and forcing temperature are effective on bud dormancy are likely overlapping and are still unclear for most species (Harrington et al. 2010; Cooke et al. 2012).

Evidence of photoperiodic mediation in late winter and early spring

Although it is commonly assumed that chilling temperatures play a crucial role in regulation of bud burst dates for European beech, the role of photoperiod remains more equivocal. There are conflicting reports on the influence of photoperiod during chilling, forcing and both phases of bud development. Some studies have claimed that photoperiod may modulate the amount of accumulated forcing temperature required to initiate bud burst of beech even after the buds were assumed to be fully chilled (Wareing 1953; Heide 1993), while Falusi and Calamassi (1990) found only a negligible effect of photoperiod. Heide (1993) reported that both photoperiod and chilling temperature together control the timing of bud burst. In particular, he found that nonchilled buds sampled in November and December are unable to develop until they have received a substantial period of chilling, even under long day conditions. Finally, by controlling both the amount of chilling and the photoperiod on beech seedlings, Falusi and Calamassi (1996) reported that long days could partially substitute winter chilling. In other words, a longer photoperiod may reduce the thermal time requirement for bud burst when chilling temperatures are insufficient to fully release the buds from dormancy. More recently, Caffarra and Donnelly (2011) reconfirmed these earlier results that photoperiod only has a strong effect on buds when they are not fully chilled. This study clearly shows a decrease in the photoperiod effect with increasing exposure to chilling temperatures.

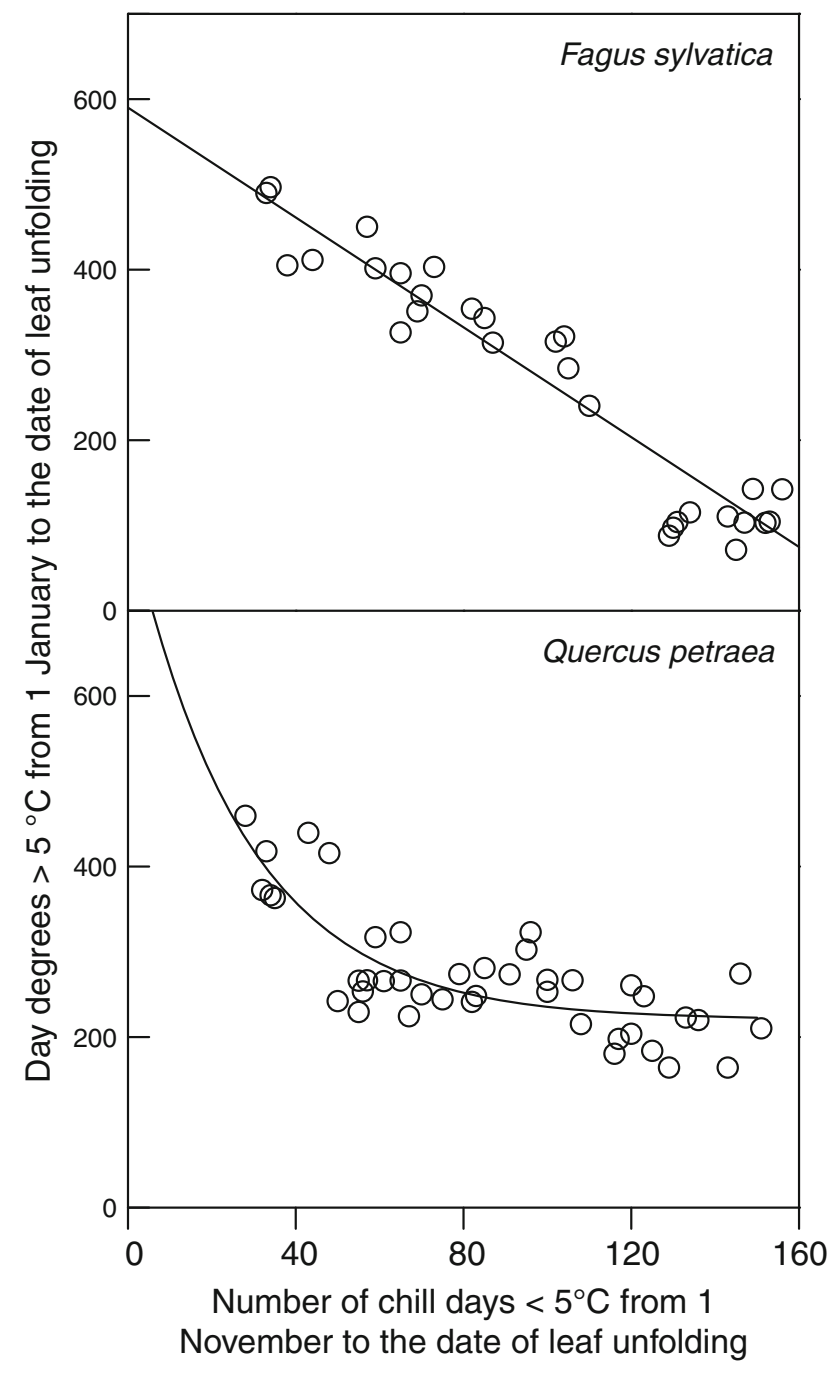

Fig. 1 Relationship between the thermal time required to bud burst, calculated as the sum of day degrees $>5{ }^{\circ} \mathrm{C}$ from 1st January to the date of leaf unfolding, and the accumulated number of chill days for populations of Fagus sylvatica and Quercus petraea monitored across two elevational gradients in Pyrenees mountains during 2005-2007 period (dataset from Vitasse et al. 2009b). A linear regression model was fitted to Fagus sylvatica $(y=-3.22 x+591)$ and a nonlinear model was fitted to Quercus petraea $\left(y=220+594 \mathrm{e}^{-0.037 \mathrm{x}}\right)$. The studied sites covered 10 populations of Fagus sylvatica and 14 populations of Quercus petraea at elevations ranging from 100 to $1,600 \mathrm{~m}$ a.s.1.. Air temperature at $2 \mathrm{~m}$ height was recorded hourly in each site, whereas leaf development was assessed every 10 days (see Vitasse et al. 2009a, b for further information)

Interactions between photoperiod and chilling/forcing temperatures

Since beech is assumed to have a very large chilling requirement, which tends to be reached only in the coldest parts of its current distribution (see previous section), it is likely that overwintered buds collected in previous experimental studies were not all fully chilled (e.g. in Wareing 1953; Heide 1993). Thus, the equivocable results of these 
studies on the role of photoperiod are controversial because they are likely to be based on a mixture of fully or partially chilled buds. The contradictory results could also arise from the way experiments are conducted. For instance, some studies used different fixed photoperiod (e.g. Heide 1993; Caffarra and Donnelly 2011) rather than gradually lengthening photoperiods (Basler and Körner 2012), or used cutting twigs (Heide 1993) rather than the whole plant (e.g. Falusi and Calamassi 1996; Caffarra and Donnelly 2011). Finally, all experiments manipulating photoperiod have been conducted on seedlings or twig cuttings which may not mirror the phenology of adult trees growing in situ (Basler and Körner 2012; Vitasse Unpublished data). The main challenge today is to quantify how the photoperiod and chilling temperatures interact together to influence the timing of beech bud burst as well as the physiological and molecular modes of action of these processes (Falusi and Calamassi 2003; Cooke et al. 2012). Indeed, there are two main different ways in which photoperiod, sensed by the plants phytochrome system, may interact with chilling and forcing temperatures:

(1) A fixed photoperiod threshold might be required to trigger dormancy release, subsequently allowing buds to respond to forcing temperature with a forcing requirement depending on the chilling fulfilment (Fig. 2a),

(2) The forcing requirement for bud burst might decrease towards its minimal value when increases in the photoperiod are detected (Fig. 2b), or the accumulation rate of forcing temperature could be accelerated by increasing bud sensitivity to forcing as photoperiod increases, or after passing a certain threshold of photoperiod (not shown).

A recent experimental study conducted on Betula pubescens combined with a new phenological model that accounts for the effects and interactions of temperature and photoperiod supports the last hypothesis, suggesting that photoperiod affects the rate of forcing accumulation (Caffarra et al. 2011). These authors also demonstrate that the photoperiod effect is greater when there is a deficit in the amount of chilling that bud experiences.

\section{What can we learn from modelling studies?}

Phenological models underline the importance of chilling temperatures in the prediction of bud burst dates for European beech

Until recently, two classes of process-based models were classically used to simulate spring phenological phases of trees. The first class of models, called hereafter the

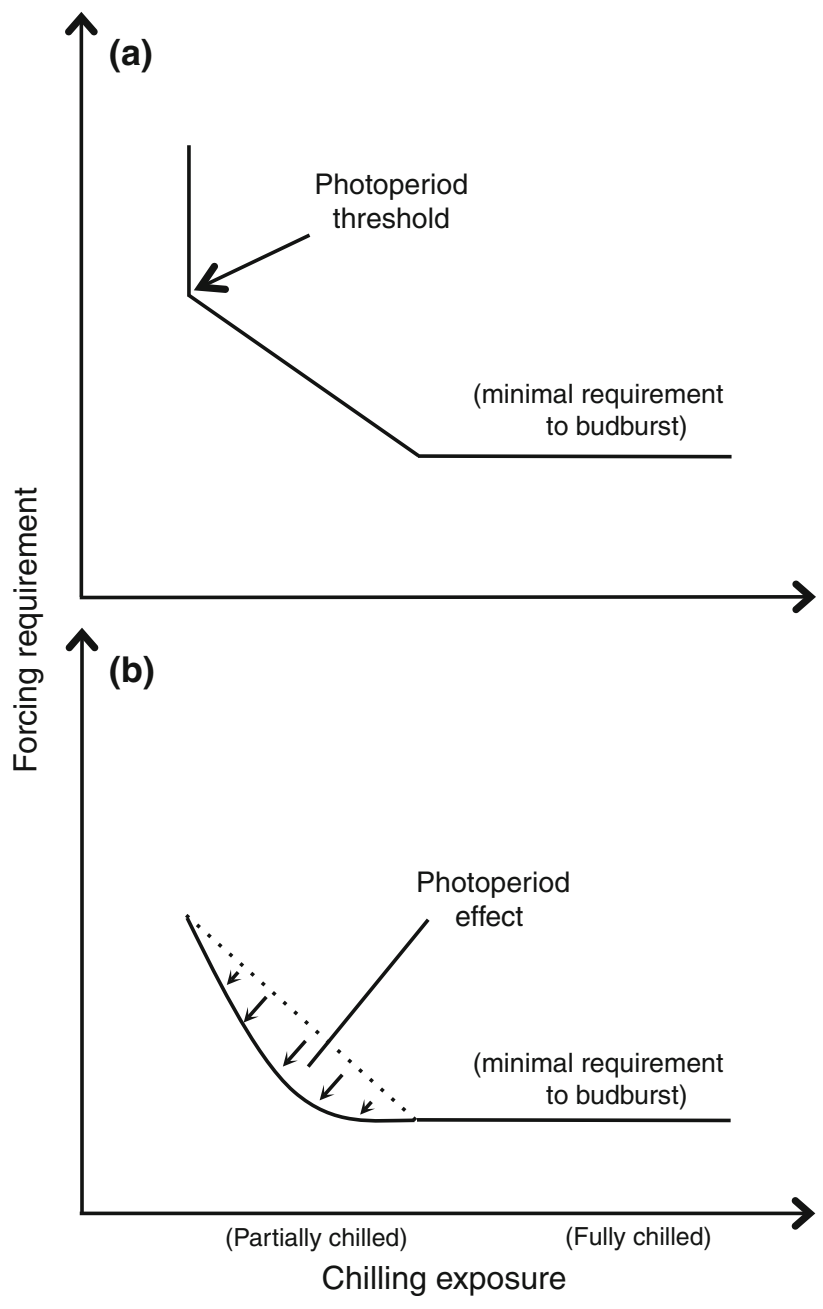

Fig. 2 Conceptual scheme on the two hypotheses for the role of photoperiod on forcing requirement in the bud burst phenology of European beech. Figure 2a. A fixed photoperiod threshold triggers dormancy release, subsequently allowing buds to respond to forcing temperature; Fig. 2b. The forcing requirement for bud burst decreases towards its minimal value when increases in the photoperiod are detected. Note that, alternatively, the accumulation rate of forcing temperature could be accelerated by increasing bud sensitivity to forcing as photoperiod increases (not drawn)

"1-phase models", considers only forcing temperature, assuming that bud burst occurs after a fixed sum of forcing units has been reached. This kind of model implicitly assumes that dormancy is fully released before the starting date of forcing accumulation. The second class of models, called hereafter the "2-phase models", considers the action of chilling temperatures during the endodormancy phase (winter deep dormancy caused by plant endogenous factors) and forcing temperatures during the ecodormancy phase (dormancy maintained by environmental factors, see Lang et al. 1987). The 2-phase models assume that the accumulation of forcing units starts and/or evolves according to the state of bud development during endodormancy (Chuine 2000; Hänninen and Kramer 2007; 
Vitasse et al. 2011) and that the critical sum of forcing units may be related to the amount of chilling units previously received (Cannell and Smith 1983; Murray et al. 1989). For most tree species, the 1-phase models have been shown to perform similarly or better than the 2-phase models (e.g. Hunter and Lechowicz 1992), suggesting that under current and past climate, the chilling requirement of trees seems to be fully met. In contrast, for beech, or in general for late-leafing species, the 2-phase models tend to outperform the 1-phase models (Kramer 1994; Thompson and Clark 2008; Vitasse et al. 2011). This is in agreement with the assumption that beech has a high chilling requirement to release dormancy and may not always saturate its chilling phase, especially in the mild winter experienced in southern and central parts of its distribution area. However, outputs from phenological models should be interpreted with caution since the state of chilling can be year to year correlated with the state of forcing (controlled by spring temperature). This correlation would give equivalent performance between 1- and 2-phase models without proving that chilling requirement is fully met. The advantage of 2-phase models would appear when the amount of chilling strongly varies from year to year and if this variation is not correlated with spring temperature.

Towards new models integrating photoperiodic effect

In spite of the improvement of predictions gained by using 2-phase models, the accuracy of these predictions is generally lower for European beech than for the other cooccurring tree species (Vitasse et al. 2011). This is likely due to the additional photoperiod sensitivity of this species besides the chilling and forcing temperature effects, as demonstrated by the experimental studies presented in the previous section. Although the influence of photoperiod in beech phenology has been previously tested in models, the results were inconsistent: Schaber and Badeck (2003) suggested strong photoperiodic control with chilling playing only a subordinate role, whereas Kramer (1994) found lower model efficiency when photoperiod was incorporated into the model. However, these two previous studies included photoperiod only as a function affecting the rate of chilling. Yet, experimental studies suggest that the photoperiod effect acts more on forcing rate via interaction with chilling requirement (Falusi and Calamassi 1996), as it was also demonstrated for Betula pubescens (Myking and Heide 1995; Caffarra et al. 2011). Hence, an original moresophisticated type of model which integrates some components of those models previously applied to beech (Kramer 1994; Chuine 2000; Hänninen and Kramer 2007) to address the effect of photoperiod on the rate of forcing accumulation and requirement, depending on prior chilling temperature, is currently being developed and performs better than classical 2-phase models on Betula pubescens (Caffarra et al. 2011). This type of model shows promise for testing our assumptions about the main environmental factors driving spring phenology in European beech.

\section{How to explain the temporal and spatial phenological patterns of European beech: towards concordance between observations and results from experiments and models?}

As mentioned in the first section, beech exhibits low variation in bud burst date from year to year or along environmental gradients in comparison with other species. This is especially true at low latitudes or elevations, i.e., in milder winter conditions. According to our theory, one would expect weak variations in the date of bud burst in warm conditions such as at low elevation in a maritime climate and higher variations in cooler winter conditions, such as at high elevation, in the northern part of Europe or with a continental climate. Indeed, under mild winter conditions, buds are likely not to reach their optimal chilling and subsequently require a higher degree of forcing before bud burst, which could potentially delay the date of bud burst. However, as photoperiod lengthens through spring, it might compensate for this delay, either by increasing the forcing accumulation rate or by decreasing the amount of forcing required to bud burst (Fig. 2b). Consequently, in such warmer climates, the effect of photoperiod should counterbalance the lack of chilling that occurs during warmer winters and early spring, leading to weak variations in bud burst dates from year to year. Similarly, buds are chilled more (or fully chilled) during cooler years, so require both a reduced amount of forcing temperature and lessened importance of photoperiod before bud burst, resulting in a more-modest delay of bud burst compared with warmer years than might otherwise be expected, i.e., a feedback loop is created that tends to stabilise bud burst date. In contrast, in cooler winter conditions as occur at high elevation, buds tend to be fully chilled, removing the possible interaction between chilling temperature and photoperiod. The bud burst dates would thus mostly depend on forcing temperatures, increasing the potential interannual variation of these dates and the correlation with spring temperatures.

This representation of the relative contributions of the three factors according to climate conditions is in line with the suggestion of Wareing (1953), 60 years ago (!), that beech bud burst dates are mainly controlled by photoperiod for southern populations and by thermic conditions for the northernmost populations. This assertion is also supported by the recorded temporal variation of bud burst dates from low and high elevation beech populations in the Swiss Alps 
during the three last decades. The leaf unfolding date of beech exhibits greater variability from year to year at high elevation than at low elevation over this period (Fig. 3). In addition, although the mean spring temperature has significantly increased during this period at both low and high elevations, a significant trend towards an earlier flushing was detected only for higher elevation (Fig. 3). These temporal trends strengthen the hypothesis that forcing temperatures predominately drive phenological variations in beech growing in climates with cold winters, whereas photoperiod and chilling reduce phenological variation at sites with mild winter conditions.

\section{Implications for climate warming}

Based on results from the different approaches cited above, the bud burst date of beech is expected not to undergo significant changes in response to global warming, in particular in the warmer part of its distribution area. The number of years with insufficient chilling temperatures to fully break dormancy is likely to increase under climate change, especially at lower latitude or elevation. As a result, the amount of forcing temperature required for bud burst may increase and offset the predicted advance of flushing in response to increasing spring temperatures. However, photoperiodic control in spring may counterbalance the lack of chilling, by decreasing the amount of forcing required or by increasing bud sensitivity to forcing temperature, leading to more conserved bud burst dates from year to year. Thus, the advance of the date of bud burst of this species in response to global warming, related to winter and spring temperatures, may be limited. However, the bud burst date of beech is expected to be more sensitive in the cold boundary of its distribution area such as at high elevation, since in such climates forcing temperature will remain the main limiting factor. These expectations are in agreement with long series of phenological observations of European beech available in Europe. For instance, in Slovenia, Cufar et al. (2012) reported earlier leaf unfolding date at high elevation over the last decades but no significant trend at low elevation. In Switzerland, observations of beech phenology along an elevational range of $200-1,440 \mathrm{~m}$ a.s.l. show the same consistent pattern: beech populations inhabiting colder climates (high elevation) exhibited a greater advance than populations inhabiting warmer climates (lower elevation) for the three last decades (Fig. 4).

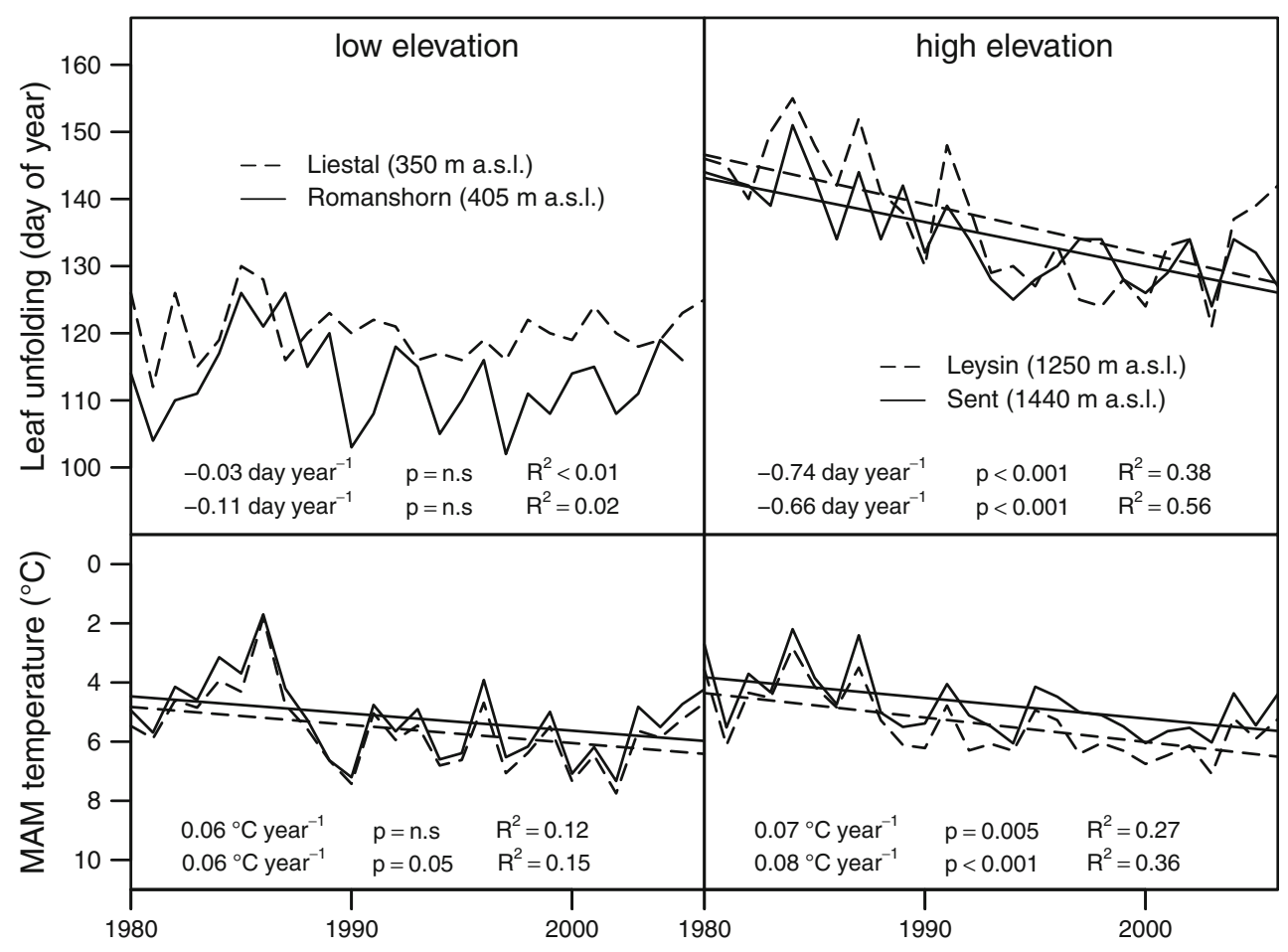

Fig. 3 Year-to-year variation of the bud burst date of beech in four sites located at low and high elevation in Switzerland for the period 1980-2006 (upper graphs) and the corresponding mean spring temperature from March to May (MAM temperature) during the same period (lower graphs). Note the reversed temperature scale. Phenological time series were provided by the Swiss Phenological
Network, MeteoSwiss. Temperature in the four sites was calculated at a $100 \times 100 \mathrm{~m}$ resolution by interpolating daily values of MeteoSwiss weather stations using the daymet method of Thornton et al. (1997). Data source: Federal Office of Meteorology and Climatology, MeteoSwiss, Switzerland; Swiss Federal Institute for Forest, Snow and Landscape Research, WSL 


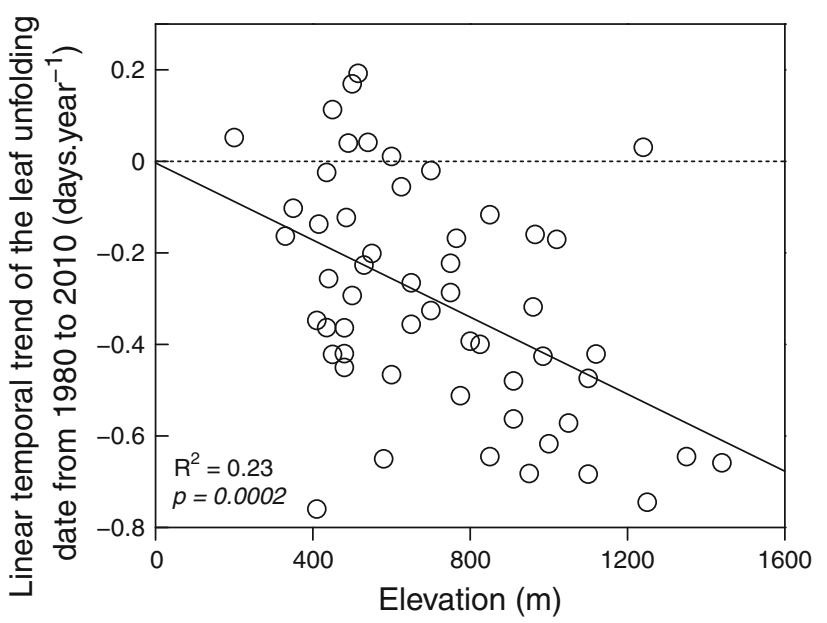

Fig. 4 Linear temporal trends of the bud burst date of beech (days.year $^{-1}, 1980-2010$ ) observed in 54 sites in Switzerland according to their elevation. Phenological time series were provided by the Swiss Phenological Network, MeteoSwiss. Only continuous time series with full coverage of the time period 1980-2010 were used

The variation in bud burst/leaf unfolding dates of European beech, and subsequently in flowering dates, is therefore expected to decrease along elevational gradients with ongoing climate warming. A smaller discrepancy in the date of flowering and bud burst between populations inhabiting different elevations could have implications for genetic diversity, enhancing the possibilities of gene crossing among populations. Finally, the growing season length may be extended less in response to the increasing temperatures for beech populations than for other photoperiod-insensitive tree species (Körner and Basler 2010). On the other hand, photoperiod-insensitive tree species, which closely track the warming spring temperatures, may be more exposed to late frost events in the future, while for beech, the dual role of chilling and forcing temperatures in combination with photoperiod could serve to protect this species against such damage (Gu et al. 2008).

\section{Conclusions}

New insights into European beech phenology have been documented from experimental and modelling studies providing robust evidence for the roles of photoperiod and temperature during winter and early spring. Thus, the bud burst date of beech is likely to be driven by both chilling and forcing temperatures with an interaction effect of the photoperiod on forcing rate (or forcing requirement) more pronounced when the chilling requirement is partially satisfied, rather than when buds are fully chilled. Finally, this review also underlines that phenology of beech follows a nonlinear trend across biogeographical gradients such as elevational gradients (Fig. 4), due to a change of the relative importance of the three main environmental factors according to climate conditions. New models that include photoperiod effect are being developed (Caffarra et al. 2011) and seem promising to fit phenological data of European beech. Fitted to bud burst data acquired from the warmest margin of beech distribution area (South Europe and low elevation) where chilling requirement of buds to fully release dormancy is likely to be only partially fulfilled, these models could be particularly relevant to examine whether their parameterization matches with the assumptions presented here. However, there are still some "black boxes" in the environmental mechanisms affecting beech phenology. First, we are not able to distinguish whether the advance of bud burst date in response to increasing chilling exposure is due to a lower requirement in forcing temperature to bud burst, an advance of the endodormancy release or both. It remains unclear whether, when buds are not fully chilled, a longer photoperiod decreases forcing requirement or increases the sensitivity of beech to forcing temperatures (higher forcing rate). Then, we are uncertain whether forcing and chilling can occur simultaneously. Finally, the last and most challenging knowledge gap is to quantify at what temperature range and temperature threshold forcing and chilling accumulation occur, and whether these temperature thresholds/ranges are fixed or change as the photoperiod increases.

Acknowledgments We are grateful to Thomas Herren for providing the phenological data of European beech from the MeteoSwiss (Swiss Federal Office of Meteorology and Climatology) and the Landscape dynamic unit, Swiss Federal Institute for Forest, Snow and Landscape Research, WSL, Birmensdorf, Switzerland for providing the modelled temperature data used in the Fig. 3. We thank Wade Jenner for linguistic revision and improvement of the text. We are grateful to two anonymous referees and for their valuable comments on a previous version of the manuscript. The research has been funded by the European Research Council (ERC) grant 233399 (project TREELIM).

\section{References}

Basler D, Körner C (2012) Photoperiod sensitivity of bud burst in 14 temperate forest tree species. Agric For Meteorol 165:73-81

Bertin RI (2008) Plant phenology and distribution in relation to recent climate change. J Torrey Bot Soc 135(1):126-146

Bolte A, Czajkowski T, Kompa T (2007) The north-eastern distribution range of European beech-a review. Forestry 80(4): 413-429

Caffarra A, Donnelly A (2011) The ecological significance of phenology in four different tree species: effects of light and temperature on bud burst. Int J Biometeorol 55(5):711-721

Caffarra A, Donnelly A, Chuine I, Jones MB (2011) Modelling the timing of Betula pubescens budburst. I. Temperature and photoperiod: a conceptual model. Clim Res 46(2):147-157

Cannell MGR, Smith RI (1983) Thermal time, chill days and prediction of budburst in Picea sitchensis. J Appl Ecol 20(3): 951-963 
Chuine I (2000) A unified model for budburst of trees. J Theor Biol 207(3):337-347

Chuine I (2010) Why does phenology drive species distribution? Philos Trans R Soc B Biol Sci 365(1555):3149-3160

Churkina G, Schimel D, Braswell BH, Xiao XM (2005) Spatial analysis of growing season length control over net ecosystem exchange. Glob Change Biol 11(10):1777-1787

Cooke JEK, Eriksson ME, Junttila O (2012) The dynamic nature of bud dormancy in trees: environmental control and molecular mechanisms. Plant, Cell Environ. doi:10.1111/j.1365-3040.2012. 02552.x

Cufar K, De Luis M, Saz MA, Crepinsek Z, Kajfez-Bogataj L (2012) Temporal shifts in leaf phenology of beech (Fagus sylvatica) depend on elevation. Trees 26(4):1091-1100

Davi H, Gillmann T, Cailleret M, Bontemps A, Fady B, Lefèvre F (2011) Diversity of leaf unfolding dynamics among tree species: new insights from a study along an altitudinal gradient. Agric For Meteorol 151(12):1504-1513

Dittmar C, Elling W (2006) Phenological phases of common beech (Fagus sylvatica L.) and their dependence on region and altitude in Southern Germany. Eur J For Res 125(2):181-188

Falusi M, Calamassi R (1990) Bud dormancy in beech (Fagus sylvatica L.). Effect of chilling and photoperiod on dormancy release of beech seedlings. Tree Physiol 6(4):429-438

Falusi M, Calamassi R (1996) Geographic variation and bud dormancy in beech seedlings (Fagus sylvatica L). Ann Sci For 53(5):967-979

Falusi M, Calamassi R (2003) Dormancy of Fagus sylvatica L. buds III. Temperature and hormones in the evolution of dormancy in one-node cuttings. Plant Biosyst 137(2):185-191

Gomory D, Paule L (2011) Trade-off between height growth and spring flushing in common beech (Fagus sylvatica L.). Ann For Sci 68(5):975-984

Gordo O, Sanz JJ (2009) Long-term temporal changes of plant phenology in the Western Mediterranean. Glob Change Biol 15(8):1930-1948

Gu L, Hanson PJ, Mac Post W, Kaiser DP, Yang B, Nemani R, Pallardy SG, Meyers T (2008) The 2007 eastern US spring freezes: increased cold damage in a warming world? Bioscience 58(3):253-262

Hänninen H, Kramer K (2007) A framework for modelling the annual cycle of trees in boreal and temperate regions. Silva Fennica 41(1):167-205

Harrington CA, Gould PJ, St Clair JB (2010) Modeling the effects of winter environment on dormancy release of Douglas-fir. For Ecol Manage 259(4):798-808

Heide OM (1993) Dormancy release in beech buds (Fagus sylvatica) requires both chilling and long days. Physiol Plant 89(1):187-191

Hunter AF, Lechowicz MJ (1992) Predicting the time of budburst in temperate trees. J Appl Ecol 29(3):597-604

Jochner S, Sparks T, Estrella N, Menzel A (2012) The influence of altitude and urbanisation on trends and mean dates in phenology (1980-2009). Int J Biometeorol 56:387-394

Körner C, Basler D (2010) Phenology under global warming. Science 327(5972):1461-1462

Kramer K (1994) Selecting a model to predict the onset of growth of Fagus sylvatica. J Appl Ecol 31(1):172-181

Kramer K (1995) Phenotypic plasticity of the phenology of seven European tree species in relation to climatic warming. Plant, Cell Environ 18(2):93-104
Kreyling J, Thiel D, Nagy L, Jentsch A, Huber G, Konnert M, Beierkuhnlein C (2012) Late frost sensitivity of juvenile Fagus sylvatica L. differs between southern Germany and Bulgaria and depends on preceding air temperature. Eur J For Res 131(3): $717-725$

Lang GA, Early JD, Martin GC, Darnell RL (1987) Endo-, para-, and ecodormancy: physiological terminology and classification for dormancy research. HortScience 22(3):371-377

Lebourgeois F, Pierrat JC, Perez V, Piedallu C, Cecchini S, Ulrich E (2010) Simulating phenological shifts in French temperate forests under two climatic change scenarios and four driving global circulation models. Int J Biometeorol 54(5):563-581

Menzel A, Estrella N, Fabian P (2001) Spatial and temporal variability of the phenological seasons in Germany from 1951 to1996. Glob Change Biol 7(6):657-666

Migliavacca M, Cremonese E, Colombo R, Busetto L, Galvagno M, Ganis L, Meroni M, Pari E, Rossini M, Siniscalco C, di Cella UM (2008) European larch phenology in the Alps: can we grasp the role of ecological factors by combining field observations and inverse modelling? Int J Biometeorol 52(7):587-605

Murray MB, Cannell MGR, Smith RI (1989) Date of budburst of fifteen tree species in Britain following climatic warming. J Appl Ecol 26(2):693-700

Myking T, Heide OM (1995) Dormancy release and chilling requirement of buds of latitudinal ecotypes of Betula pendula and B. pubescens. Tree Physiol 15(11):697-704

Polgar CA, Primack RB (2011) Leaf-out phenology of temperate woody plants: from trees to ecosystems. New Phytol 191(4): 926-941

Rötzer T, Grote R, Pretzsch H (2004) The timing of bud burst and its effect on tree growth. Int J Biometeorol 48(3):109-118

Schaber J, Badeck FW (2003) Physiology-based phenology models for forest tree species in Germany. Int J Biometeorol 47(4): 193-201

Studer S, Appenzeller C, Defila C (2005) Inter-annual variability and decadal trends in alpine spring phenology: a multivariate analysis approach. Clim Change 73(3):395-414

Thompson R, Clark RM (2008) Is spring starting earlier? Holocene 18(1):95-104

Thornton PE, Running SW, White MA (1997) Generating surfaces of daily meteorological variables over large regions of complex terrain. J Hydrol 190(3-4):214-251

Vitasse Y, Delzon S, Dufrene E, Pontailler JY, Louvet JM, Kremer A, Michalet R (2009a) Leaf phenology sensitivity to temperature in European trees: do within-species populations exhibit similar responses? Agric For Meteorol 149(5):735-744

Vitasse Y, Porte AJ, Kremer A, Michalet R, Delzon S (2009b) Responses of canopy duration to temperature changes in four temperate tree species: relative contributions of spring and autumn leaf phenology. Oecologia 161(1):187-198

Vitasse Y, Francois C, Delpierre N, Dufrene E, Kremer A, Chuine I, Delzon S (2011) Assessing the effects of climate change on the phenology of European temperate trees. Agric For Meteorol 151(7):969-980

Wareing PF (1953) Growth studies in woody species. V. Photoperiodism in dormant buds of Fagus sylvatica. Physiol Plant 6(4): 692-706 